\title{
Epidemiology of Endometrial Neoplasia
}

\author{
David Schottenfeld, MD, MSc \\ Department of Epidemiology, University of Michigan School of Public Health, \\ Ann Arbor, MI 48109-2029
}

\begin{abstract}
Though among U.S. women endometrial cancer is the most common invasive gynecological cancer, it has a relatively favorable prognosis. From 1986-1990, approximately 19\% of U.S. Surveillance, Epidemiology and End Results (SEER) Program cases were diagnosed in women less than 55 years of age; however, the age-specific incidence (per 100,000) peaked at 70-74 years (110.7), which was 2.85 times the rate reported at 50-54 years (38.9). The incidence under 50 years was 2.19 times higher in U.S. White compared with U.S. Black women; for uterine corpus cancers diagnosed at 50 years and older, the ratio declined but continued to be elevated in Whites (1.46). In contrast, average annual age-adjusted mortality (per 100,000) from 1986-1990 for uterine corpus cancer (1970 U.S. standard) was almost twice as high in U.S. Black women (6.0) as in U.S. White women (3.3). The determinants of age-specific elevated risks in mortality, in contrast to the lesser age-specific risks in incidence experienced by U.S. Black women compared with U.S. White women, may be explored with respect to socioeconomic and cultural factors that influence the distribution of epidemiologic risk factors such as reproductive history, choice of contraception methods, hormone replacement therapy, obesity, and dietary factors; age-specific prevalence of hysterectomy for other gynecological conditions; quality of medical care and surveillance practices; genetic factors influencing susceptibility; and tumor-associated biological factors. The majority of risk factors and medical conditions associated with endometrial cancer are related directly or indirectly to the levels and metabolic effects of the reproductive hormones, namely estrogens and progestogens. The molecular, genetic, and epidemiologic characterization of endometrial cancer is attempting to delineate the multiple steps in the natural history of estrogen-induced or estrogen-responsive neoplasms. (C) 1995 Wiley-Liss, Inc.
\end{abstract}

Key words: Endometrial cancer, epidemiologic risk factors

Carcinoma of the uterine corpus is the most common invasive gynecologic cancer in the U.S. In U.S. White women during 1973-1990, the ageadjusted incidence (per 100,000) for cancer of the uterine corpus peaked around 1974-1976 (32.9), and then declined significantly, so that by 1990 , the incidence was 22.7 , or about $30 \%$ less than the incidence in the mid-1970s [1]. During the same time period, age-adjusted mortality de-

Address correspondence to David Schottenfeld, MD, MSc, Department of Epidemiology, University of Michigan School of Public Health, 109 Observatory Street, Ann Arbor, MI 48109-2029.

(C) 1995 Wiley-Liss, Inc. clined by $42 \%$ in U.S. White women under 50 years, and by $23 \%$ in women 50 years and over. Age-specific incidence rates increased more rapidly in women under 50 years, at least doubling in each five-year age group after age 35 years, than in women 50 years and over, where the rate of increase in each five-year age group between $50-74$ years was only $27 \%$; after age 75 years, the incidence rates declined slightly in White and Black women (Fig. 1). During 1986-1990, approximately $19 \%$ of U.S. Surveillance, Epidemiology and End Results (SEER) cases were diagnosed in women < 55 years of age; the age-specific incidence peaked at 70-74 years (110.7), which was 2.85 times the rate reported at $50-54$ years (38.9). 


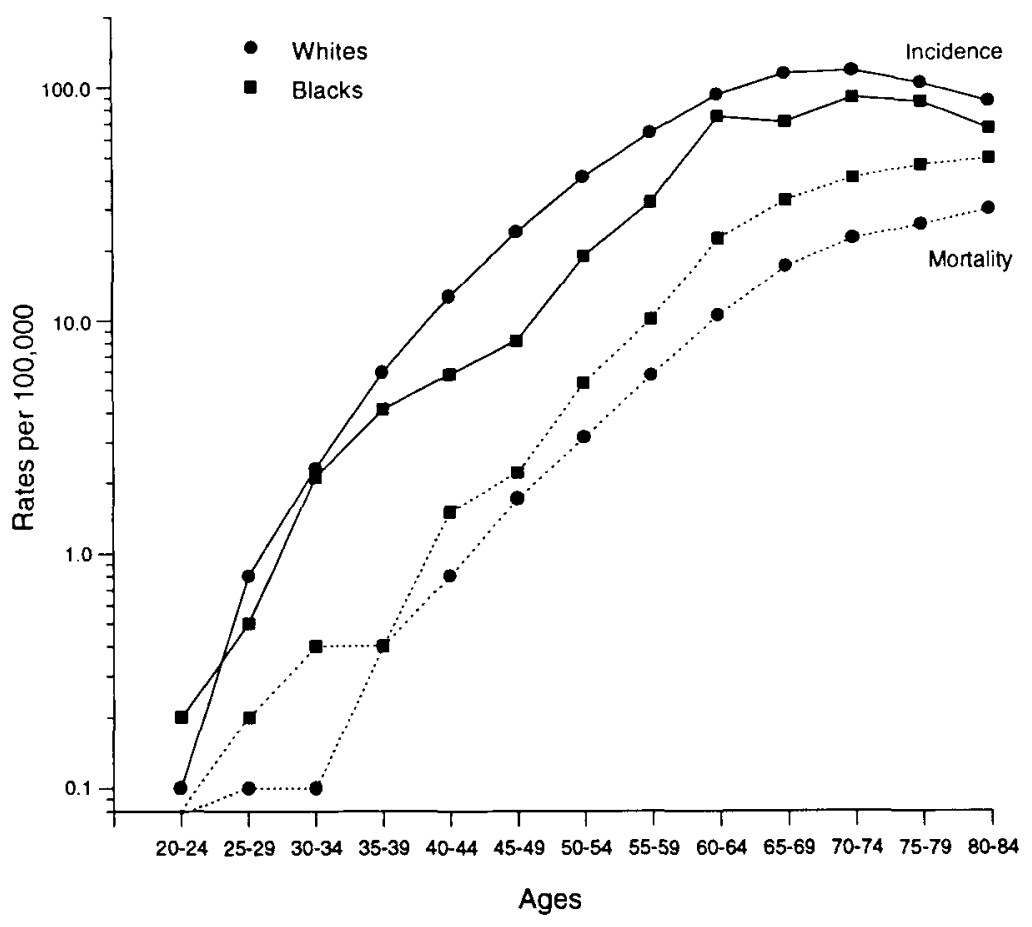

Fig. 1. Age-specific incidence and mortality for cancer of the uterine corpus, by race, U.S. SEER, 1986-1990.

The incidence of uterine corpus cancer diagnosed under age 50 years was 2.2 times higher in U.S. White compared with Black women; for uterine corpus cancer diagnosed in women 50 years and over, the incidence or risk in U.S. Whites relative to U.S. Blacks declined, but remained elevated (1.5). During the period between 1973-1990, the age-adjusted incidence rates in U.S. Black women under age 50 years decreased by $33.7 \%$, but increased slightly by $16.4 \%$ over age 50 .

In contrast, average annual age-adjusted mortality (per 100,000) in 1986-1990 for uterine corpus cancer (including deaths certified as "uterus, not otherwise specified") was almost twice as high in U.S. Blacks (6.0) than in U.S. Whites (3.3). However, between 1973-1990, mortality declined in women $<50$ years by about $62 \%$ in Black women and $42 \%$ in White women; in women 50 years of age and older, mortality declined by $17 \%$ in Black and 23\% in White women. The agespecific mortality rates (1986-1990) were consistently higher in U.S. Black women compared with U.S. White women, particularly after age 50 years (Fig. 1).

\section{U.S. BLACK-WHITE DIFFERENCES: NURTURE OR NATURE?}

A pattern for cancer of the uterine corpus, at least since the early 1970s in the U.S., has been elevated age-specific incidence rates in Whites compared with Blacks, but elevated age-specific mortality rates and case fatality rates in Blacks who developed invasive disease. The ratio of age-adjusted mortality to age-adjusted incidence for uterine corpus cancer was 0.41 in U.S. Black women and 0.15 in U.S. White women, suggesting that the likelihood of a case fatality for each incident case in Black women was at least twice that in White women. Excessive mortality experienced by U.S. Blacks is being explored with respect to behavioral and medical care characteristics correlated with socioeconomic status, the distribution of epidemiologic risk factors and their association with causal mechanisms, tumorassociated biological factors, and genetic factors influencing susceptibility or interacting with sex steroid hormone metabolism. Socioeconomic status and cultural factors which are correlated with race may influence access to or quality of medi- 
cal care; knowledge, attitudes and behavior with respect to screening and early detection practices; choice of contraception methods and use of postmenopausal hormone replacement therapy; and the distribution of other life-style risk factors associated with endometrial adenocarcinoma incidence ( $92 \%$ of cancers of the uterine corpus) and/or survival rates.

White women in the SEER population diagnosed with uterine corpus cancer in 1983-1989 had a five-year relative survival rate in all stages of $93.2 \%$ under age 50 years and $83.6 \%$ for age 50 years and older. The comparable five-year relative survival in Black women was $80.6 \%$ and $51.1 \%$, respectively. The proportion with localized disease was $23 \%$ higher (75\% compared with $52 \%$ ) in Whites, who exhibited significantly better five-year relative survival than Blacks after controlling for stage and grade of differentiation (Table I). Black women presented with more advanced stages of poorly differentiated tumors compared with White women. Most of the decrease in age-adjusted incidence in Whites for uterine corpus cancer since the late 1970s was for adenocarcinomas, including sub-groups classified with squamous metaplasia; from 1973-1987, the age-adjusted incidence of adenocarcinoma of the endometrium (per 100,000) in Whites decreased from 28.7 to 21.1 , but remained relatively stable in Blacks (11.3 to 10.6). Adenocarcinomas accounted for more than $90 \%$ of cancers of the uterine corpus in Whites, in contrast to $78 \%$ in Blacks. In contrast, sarcomas (e.g., leiomyosarcoma, endometrial stromal sarcoma) and mixed
Müllerian and mesodermal tumors, generally of poor prognosis, were relatively more frequent in Blacks (19\%) than in Whites (5-6\%) [2]. Clear cell, serous, and adenosquamous (other uncommon subtypes of carcinoma) were associated with poorer prognosis, higher grade of differentiation, occurred generally in older women, and have not varied in incidence over time or been associated with estrogen-induced endometrial neoplasia.

\section{ENDOGENOUS AND EXOGENOUS ESTROGENS}

Women with elevated endogenous estrogen levels, as in obesity, the Stein-Leventhal syndrome, and estrogen-secreting tumors of the ovary, are at increased risk for endometrial cancer and its morphologic precursor condition, atypical endometrial hyperplasia [3]. Estradiol is normally the most potent endogenous estrogen, but estrone assumes significance in postmenopausal women. Estrogens increase the mitotic rate of endometrial cells. Progestins oppose this action by decreasing the concentration of estrogen receptors, and by causing differentiation of the endometrial cells to a secretory state [4].

\section{OBESITY}

Obesity is a chronic metabolic disorder characterized by an excess of body fat. The increased risk of endometrial cancer is associated with increased relative weight (\% excess weight cor-

TABLE I. Five-Year Relative Survival (\%) by Race, Year of Diagnosis, and Grade of Differentiation for Uterine Corpus Cancer in Women 50 Years and Over

\begin{tabular}{|c|c|c|c|c|c|c|c|c|}
\hline \multirow[b]{3}{*}{ Year of Diagnosis } & \multicolumn{8}{|c|}{ Grade of Differentiation $^{a}$} \\
\hline & \multicolumn{2}{|c|}{ I } & \multicolumn{2}{|c|}{ II } & \multicolumn{2}{|c|}{ III } & \multicolumn{2}{|c|}{ IV } \\
\hline & $W^{+}$ & $\mathrm{B}^{+}$ & $W$ & $B$ & W & B & $W$ & B \\
\hline 1974-1976 & 99.2 & 93.9 & 91.6 & 61.8 & 72.5 & 40.9 & 48.9 & $-{ }^{*}$ \\
\hline $1977-1979$ & 97.0 & 81.5 & 89.1 & 66.7 & 63.0 & 40.9 & 43.7 & -- \\
\hline $1980-1982$ & 97.7 & 81.5 & 86.1 & 66.7 & 59.4 & 22.7 & 39.3 & -- \\
\hline 1983-1989 & 98.3 & 86.7 & 90.6 & 68.5 & 59.5 & 35.2 & 45.2 & 34.3 \\
\hline
\end{tabular}

${ }^{+}$White (W), Black (B); ${ }^{a}$ Grade I = Well differentiated; Grade II = Mostly differentiated; Grade III = Poorly differentiated; Grade IV $=$ Undifferentiated; *Statistic could not be calculated. 
rected for age, sex, and frame), body mass index (Quetelet's BMI = weight $/$ height $^{2}$ ), waist-to-thigh circumference ratio (WTR), or waist-to-hip circumference ratio (WHR) [5-8]. Cancer of the endometrium was the site most strongly associated with obesity in the American Cancer Society Prospective Study I, with women who were $40 \%$ overweight exhibiting more than a four-fold increase in mortality [9]. The relative risk of endometrial cancer in relation to measures of extreme obesity (e.g., $\geq 130 \%$ above the standard) and an anthropometric pattern of abdominal (visceral and subcutaneous) fat distribution may range between 2-5 times the risk in a referent or control group [10-12]. Whereas the lifetime risk of being diagnosed with endometrial cancer in the U.S. is $2.7 \%$, the cumulative risk increases to about $9-10 \%$ in extremely obese women (BMI $\geq 30$ ). Based on estimates of relative risk and prevalence of obesity in U.S. women 45-64 years of age, excessive weight (standardized for height) and a central or android pattern of fat distribution may account for $17 \%$ to $46 \%$ of endometrial cancer incidence in postmenopausal women (Table II).

Obesity may increase the risk of endometrial cancer because of the increased frequency of anovulatory cycles in premenopausal women and by altering estrogen and androgen metabolism in postmenopausal women (Table III). With the cessation of ovulation at the onset of menopause, estrogen and androgen metabolism shifts from the ovary to the adrenal and adipocytes in subcutaneous and visceral tissues. Obesity, especially abdominal adiposity, increases circulating estrogen levels by enhancing the availability of androstenedione from the adrenal and the efficiency of its metabolic conversion or aromatization to estrone and estradiol, and by decreasing the level and binding of sex hormone-binding

TABLE II. Summary of Relative, Cumulative Lifetime (0-74 years) ${ }^{+}$ and Population Attributable Risks of Endometrial Cancer in United States Obese* Women

\begin{tabular}{|c|c|}
\hline \multicolumn{2}{|l|}{ Risk Measure } \\
\hline Relative risk & $2-5$ times the risk in the referent population \\
\hline Cumulative lifetime risk & about $9-10 \%$ \\
\hline $\begin{array}{l}\text { Population attributable risk } \\
(\%), 45-64 \text { years }\end{array}$ & $17-46 \%$ \\
\hline
\end{tabular}

TABLE III. Endocrine Changes in Obesity

\section{Ovary}

Normal or increased total and free estradiol

Normal or increased total and free estrone

Decreased hydroxylation at the $2 \alpha$ and $17 \alpha$ positions of estradiol

\section{Adipose Tissue}

Increased conversion of androgen to estrogen

\section{Adrenal}

Increased androgens (testosterone, $5 \alpha$-dihydrotestosterone, and dehydroepiandrosterone) 
globulin with estrogen which results in the increased availability and biologic activity of free estrogens (and androgens) [13-15]. There is a significantly positive correlation between increases in androgenic activity (i.e., plasma levels of free testosterone, dihydrotestosterone, androstenedione and dehydroepiandrosterone) and increasing WHR (or WTR). Increasing androgenic activity is a determinant of body fat distribution, and is associated with decreasing peripheral insulin sensitivity, abnormal glucose tolerance, and increased synthesis of very low density lipoproteins [16].

\section{ESTROGEN REPLACEMENT THERAPY (ERT)}

By the mid 1970s, a substantial number of postmenopausal women in the U.S. had been using conjugated estrogens of equine origin during the 1960s and early 1970s. During the 1970s, the incidence of endometrial cancer increased significantly among White women ages 50-64, despite the competing concurrent trend of in- creasing hysterectomy rates for benign gynecologic diseases [17]. Following the declining trend of prescribing estrogen without progestin during the late 1970s, endometrial cancer incidence diminished (Fig. 2). A parallel increase in exogenous estrogen prescriptions and increasing incidence of endometrial cancer was also described in Denmark. More than 40 case-control and cohort studies of ERT and endometrial cancer have been conducted in various high-usage and lowusage populations [18-20].

In general, use of unopposed estrogens for one or more years was associated with relative risks ranging from 1.5 to 10.0 . Odds ratios were generally higher in case-control studies that used controls with nongynecologic diseases rather than gynecologic (excluding cancer) diseases. Duration of use and cumulative dose were significantly associated with the strength of relative risk. Although most studies have recorded a higher level of risk in current users, persistent risks after discontinuation of ERT ranged from 5-15 years. Most studies emphasized that exogenous factors affecting circulating estrogen levels

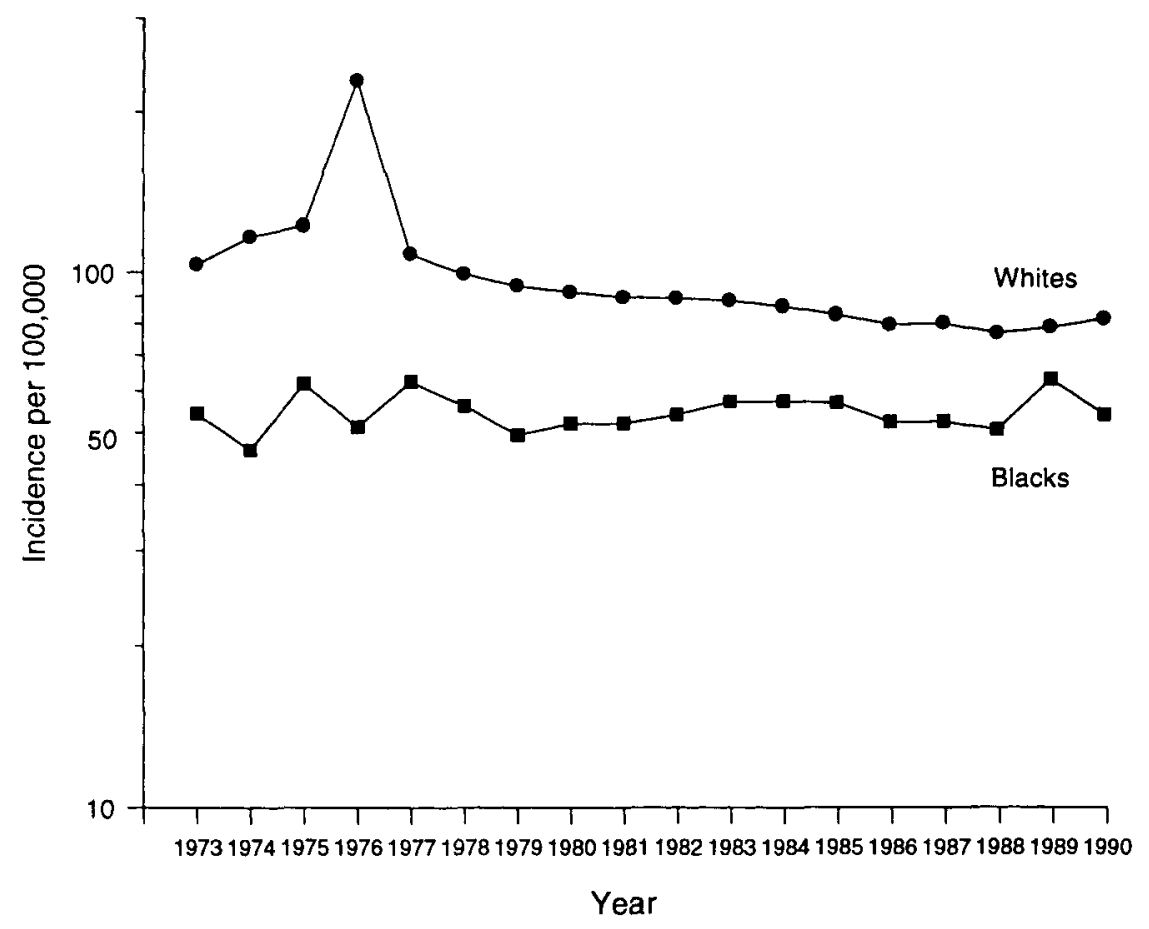

Fig. 2. Age-adjusted incidence per 100,000 , in women 50

U.S. SEER, 1986-1990. years and older, for cancer of the uterine corpus, by race, 
were correlated with endometrial cancers of low grade of differentiation, superficial invasion into the myometrium, and other favorable prognostic characteristics.

Progesterone secretion during the luteal phase of the menstrual cycle modulates the mitotic effects of estrogenic stimulation. During the late secretory phase prior to menstruation, progesterone secretion diminishes rapidly, and apoptotic bodies appear in association with the marked attenuation in expression of BCL-2 protein [21]. Epidemiologic studies provide compelling evidence of the benefits of adding progestogen when initiating ERT; however, the chemopreventive potential of progestogen will be limited to estrogen-responsive neoplasms $[22,23]$.

\section{Oral Contraceptives (OCs)}

In the 1970s, an increased risk of endometrial cancer was reported in women using sequential
OCs, with relatively high-dose estrogen followed by progesterone. For this reason, sequential OCs such as Oracon were removed from the market in the mid-1970s. In contrast, use of combination OCs was shown to decrease the risk of endometrial cancer by about $50 \%$ when compared with non-users. The protective effect of OCs was evident after a minimum of one to three years of use, was dose-related, and persisted for at least five years after cessation of use $[24,25]$.

\section{COMPARING RISK FACTORS FOR ENDOMETRIAL AND BREAST CARCINOMA}

Indigenous populations from countries at high or low risk of uterine corpus cancer tend to show similar levels of risk for breast cancer (Table IV). In addition, these patterns change with gradual acculturation after migration, so that after one or two generations, the incidence rates approximate the levels of risk manifested by the host country.

TABLE IV. Comparison of Age-Standardized Incidence Rates, Selected Countries, Uterine Corpus and Breast Cancer, 1985 [32]

\begin{tabular}{|c|c|c|c|}
\hline & Country & Uterine Corpus & Breast \\
\hline \multirow{11}{*}{ I. } & High & & \\
\hline & Canada & 15.8 & 71.1 \\
\hline & Denmark & 15.3 & 68.6 \\
\hline & Connecticut (White) & 17.6 & 88.9 \\
\hline & Hawaii: & & \\
\hline & White & 18.9 & 99.3 \\
\hline & Chinese & 15.6 & 75.6 \\
\hline & Japanese & 15.1 & 64.0 \\
\hline & New Zealand: Maori & 16.4 & 64.0 \\
\hline & Sweden & 12.7 & 62.5 \\
\hline & US SEER: White & 19.2 & 89.2 \\
\hline \multirow[t]{9}{*}{ II. } & Intermediate & & \\
\hline & Finland & 11.8 & 52.5 \\
\hline & France, Calvados & 10.2 & 60.8 \\
\hline & Iceland & 10.9 & 69.7 \\
\hline & Israel: Jews & 10.3 & 64.7 \\
\hline & New Zealand: Non-Maori & 9.3 & 64.3 \\
\hline & England and Wales & 8.0 & 56.1 \\
\hline & US SEER: Black & 9.7 & 65.0 \\
\hline & Italy, Genoa & 9.2 & 65.8 \\
\hline \multirow[t]{5}{*}{ III. } & Low & & \\
\hline & China, Shanghai & 2.9 & 21.2 \\
\hline & India, Bombay & 2.3 & 24.6 \\
\hline & Japan, Miyagi & 3.2 & 27.8 \\
\hline & Israel: Non-Jews & 2.8 & 17.0 \\
\hline
\end{tabular}


TABLE V. Comparison of Risk Factors for Cancer of the Endometrium and Breast

\begin{tabular}{|c|c|c|c|}
\hline & & Endometrium & Breast \\
\hline \multirow[t]{5}{*}{ I. } & Menstruation & & \\
\hline & Early age at menarche & + & + \\
\hline & Early age at natural (or surgical) menopause & - & - \\
\hline & Late age at natural menopause & + & + \\
\hline & $\begin{array}{l}\text { Years between menarche and menopause, } \\
\text { excluding pregnancies, lactation-months, } \\
\text { and/or duration of OC use }\end{array}$ & + & + \\
\hline \multirow[t]{7}{*}{ II. } & Pregnancy & & \\
\hline & Married, never pregnant & + & + \\
\hline & Early age, first full-term pregnancy & 0 & - \\
\hline & Multiple full-term pregnancies & - & - \\
\hline & Late age ( $>35 \mathrm{yr}$ ) first full-term pregnancy & 0 & + \\
\hline & Late age (> $35 \mathrm{yr}$ ) last full-term pregnancy & - & $?$ \\
\hline & Cumulative number of lactating months & 0 & - \\
\hline \multirow[t]{3}{*}{ III. } & Family History & & \\
\hline & Organ-specific & + & + \\
\hline & $\begin{array}{l}\text { Multiple organ primary cancers: } \\
\text { ovary, breast, endometrium, colon }\end{array}$ & + & + \\
\hline \multirow[t]{3}{*}{ IV. } & $\begin{array}{l}\text { Obesity: Excess average weight, weight gain, } \\
\text { and/or central versus peripheral obesity }\end{array}$ & & \\
\hline & Premenopausal women & + & $-/ 0$ \\
\hline & Postmenopausal women & + & + \\
\hline \multirow[t]{2}{*}{ V. } & Oral Contraceptive Steroids & & \\
\hline & Estrogen/Progestin & - & $+/ ?$ \\
\hline \multirow[t]{3}{*}{ VI. } & Estrogen Replacement Therapy & & \\
\hline & Without Progestin & + & + \\
\hline & With Progestin & $-* *$ & $+/ ?$ \\
\hline \multirow[t]{4}{*}{ VII. } & Nutrition & & \\
\hline & Fat (total, saturated) & + & $+/ ?$ \\
\hline & Calories & + & $+/ ?$ \\
\hline & Fruits and vegetables & $-/ ?$ & $-/ ?$ \\
\hline VIII. & Tobacco & - & 0 \\
\hline IX. & Ethanol & 0 & + \\
\hline X. & Physical Activity & - & - \\
\hline
\end{tabular}

A review and comparison of risk factors for cancer of the endometrium and breast inferred from epidemiologic studies is helpful in formulating causal hypotheses [Table V]. The hypothesis of "unopposed estrogen" and the chemopreventive action of progestins is compelling for cancer of the endometrium in premenopausal and postmenopausal women [17]. Target tissues responsive to estrogens and progesterone contain high- affinity receptor proteins. An important difference between breast and endometrium is the mechanism of action of progesterone and synthetic progestins. The antagonistic effects of progestins on the stimulating effects of estrogens are evident in normal and neoplastic endometrial tissues. However, as suggested by epidemiologic investigations, progestins do not appear to have the same protective effect for breast cancer, and 
may even be tumorigenic $[26,27]$. In the normal breast, mitotic activity of ductal and lobular epithelium increases during the luteal phase rather than the follicular phase of the menstrual cycle. A rational approach to the primary prevention of endometrial cancer would include adding progestin to estrogen therapy and avoiding obesity. The relative protective effects demonstrated for regular physical activity and a prudent and balanced diet with a high intake of carotenoids and enriched with the antioxidative properties of green and yellow vegetables may be correlated with estrogen metabolism and body fat topography. It has been hypothesized that environmental and genetic factors that either decrease $16 \alpha$ hydroxylation or increase $2 \alpha$-hydroxylation of estradiol may protect against endometrial cancer [28-30].

\section{REFERENCES}

1. Miller BA, Ries LAG, Hankey BF, Kosary CL, Harras A, Devesa SS, Edwards BK (eds): SEER Cancer Statistics Review: 1973-1990. Bethesda, MD: National Cancer Institute; NIH publication 93-2789, 1993.

2. Platz CE, Benda JA: Female genital tract cancer. Cancer 75:270-294, 1995.

3. Pettersson B, Adami H, Lindgren A, Hesselius I: Endometrial polyps and hyperplasia as risk factors for endometrial carcinoma. Acta Obstet Gynecol Scand 64:653-659, 1985.

4. Whitehead MI, Townsend PT, Pryse-Davies J, Ryder TA, King JB: Effects of estrogens and progestins on the biochemistry and morphology of the postmenopausal endometrium. N Engl J Med 305:1599-1605, 1981.

5. Folsom AR, Kaye SA, Potter JD, Prineas RJ: Association of incident carcinoma of the endometrium with body weight and fat distribution in older women: Early findings of the Iowa women's health study. Cancer Res 49:6828-6831, 1989.

6. Ewertz M, Schou G, Boice JD Jr: The joint effect of risk factors on endometrial cancer. Eur J Cancer 24:189-194, 1988.

7. Elliott EA, Matanoski GM, Rosenshein NB, Grumbine FC, Diamond EL: Body fat patterning in women with endometrial cancer. Gynecol Oncol 39:253-258, 1990.

8. Austin H, Austin JM Jr, Partridge EE, Hatch KD, Shingleton HM: Endometrial cancer, obesity, and body fat distribution. Cancer Res 51:568-572, 1991.

9. Lew EA, Garfinkel L: Variation in mortality by weight among 750,000 men and women. J Chronic Dis 32:563-576, 1979.

10. Lapidus L, Helgesson O, Merck C, Bjorntorp P: Adipose tissue distribution and female carcinomas. A 12year follow-up of participants in the population study of women in Gothenburg, Sweden. Int J Obesity 12:361-368, 1988.

11. Schapria DV, Kumar NB, Lyman GH, Cavanagh D, Roberts WS, La Polla J: Upper-body fat distribution and endometrial cancer risk. JAMA 266:1808-1811, 1991.

12. Swanson CA, Potischman N, Wilbanks GD, Twiggs LB, Mortel R, Berman ML, Barrett RJ, Baumgartner $\mathrm{RN}$, Brinton LA: Relation of endometrial cancer risk to past and contemporary body size and body fat distribution. Cancer Epidemiol Biomarkers Prev 2:321-327, 1993.

13. MacDonald PC, Siiteri PK: The relationship between the extraglandular production of estrone and the occurrence of endometrial neoplasia. Gynecol Oncol 2:259-263, 1974.

14. Davidson BJ, Gambone JC, Lagasse LD, Castaldo JW, Hammond GL, Siiteri PK, Judd HL: Free estradiol in postmenopausal women with and without endometrial cancer. J Clin Endocrinol Met 52:404-408, 1981.

15. Evans DJ, Hoffman RG, Kalkhoff RK, Kissebah AH: Relationship of androgenic activity to body fat topography, fat cell morphology, and metabolic aberrations in premenopausal women. J Clin Endocrinol Metab 57:304-309, 1983.

16. Kissebah AH, Freedman DS, Peiris AN: Health risks of obesity. Med Clin N America 73:111-138, 1989.

17. Henderson BE, Ross R, Bernstein L: Estrogens as a cause of human cancer: The Richard and Hinda Rosenthal Foundation Award Lecture. Cancer Res 48:246-253, 1988.

18. Elwood JM, Cole P, Rothman KJ, Kaplan SD: Epidemiology of endometrial cancer. J Natl Cancer Inst 59:1055-1060, 1977.

19. Kelsey JL, LiVolsi VA, Holford TR, Fischer DB, Mostow ED, Schwartz PE, O'Connor T, White CA: A case-control study of cancer of the endometrium. Am J Epidemiol 116:333-342, 1982.

20. Brinton LA, Hoover RN: Epidemiology of gynecologic cancers. In Hoskins WJ, Perez CA, Young RC (eds): "Principles and Practices of Gynecologic Oncology." Philadelphia: J.B. Lippincott Co., 1992, pp 3-26.

21. Otsuki $Y$, Misaki $O$, Sugimoto $O$, Ito $Y$, Tsujimoto $Y$, Akao Y: Cyclic bcl-2 gene expression in human uterine endometrium during menstrual cycle. Lancet 344:28-29, 1994.

22. Tseng I, Gurpide E: Induction of human endometrial estradiol dehydrogenase by progestins. Endocrinology 97:825-833, 1975.

23. Persson I, Adami H-O, Bergkvist L, Lindgren A, Petterson B, Hoover R, Schairer C: Risk of endometrial cancer after treatment with estrogens alone or in conjunction with progestogens: Results of a prospective study. Br Med J 298:147-151, 1989.

24. Weiss NS, Sayvetz TA: Incidence of endometrial cancer in relation to use of oral contraceptives. $\mathrm{N}$ Engl J Med 302:551-554, 1980.

25. Cancer and Steroid Hormone Study of the Centers for Disease Control and the National Institute of Child Health and Human Development: Combina- 
tion oral contraceptive use and the risk of endometrial cancer. JAMA 257:796-800, 1987.

26. Stanford JL, Thomas DB: Exogenous progestins and breast cancer. Epidemiol Rev 15:98-107, 1993.

27. Pike MC, Spicer DV, Dahmoush L, Press MF: Estrogens, progestogens, normal breast cell proliferation, and breast cancer risk. Epidemiol Rev 15:17-35, 1993.

28. Barbone F, Austin H, Partridge EE: Diet and endometrial cancer: A case-control study. Am J Epidemiol 137:393-403, 1993.

29. Potischman N, Swanson CA, Brinton LA, McAdams M, Barrett RJ, Berman ML, Mortel R, Twiggs LB, Wilbanks, GD, Hoover RN: Dietary associations in a case-control study of endometrial cancer. Cancer Causes Control 4:239-250,1993.

30. Brinton LA, Hoover RN, and Endometrial Cancer Collaborative Group: Estrogen replacement therapy and endometrial cancer risk: Unresolved issues. Obstet Gynecol 81:265-271, 1993.

31. Epstein FH, Higgins M: Epidemiology of obesity. In Björntorp P, Brodoff BN (eds): "Obesity." Philadelphia: J.B. Lippincott Co., 1992, pp 330-342.

32. Parkin DM, Muir CS, Whelan SL, Gao VT, Ferlay J, Powell J: Cancer Incidence in Five Continents. Vol. VI. IARC Sci Publ 120, 1992. 